УДК 159.9.072.43

\title{
ДИНАМИКА СМЫСЛОВЫХ СОСТАВЛЯЮЩИХ МЕНТАЛЬНОСТИ ПОКОЛЕНИЙ
}

\author{
Пищик Влада Игоревна \\ Сиврикова Надежда Валерьевна
}

Представлено исследование жизненных смыслов трех групп поколений. Анализируются исследования российских и зарубежных исследователей, показывающие, что поколение - это группа людей со сформированными в подростковом возрасте ченностно-смысловыми основаниями ментальности, отличными от других поколений. Эмпирически, посредством методики Н. Л. Ивановой, выявлена поколенческая идентификация групп: советская, переходная, постсоветская. Посредством методики В. Ю. Котлякова обнаружено, что в группе подростков ведущими выступили семейные, коммуникативные и альтруистические смыслы. В группе молодежи представлены когнитивные, семейные, смыслы самореализации и экзистенциальные смыслы. В группе пенсионеров - экзистенциальные, семейные и коммуникативные. Делается вывод о статистически значимых различиях смыслов в группах различной поколенческой идентичности.

Ключевые слова: поколения, ментальность, поколенческий подход, смысловая сфера, смена поколений.

\section{THE DYNAMICS OF SENSE COMPONENTS OF THE MENTALITY OF GENERATIONS}

\section{Pishchik Vlada Igorevna \\ Sivrikova Nadezhda Valer'evna}

The article focuses on the study of life's senses of three groups of generations. The authors analyze researches of Russian and foreign researchers showing that generation is a group of people with sense-value bases of mentality which have been formed in adolescence and differ from other generations. By means of N. L. Ivanova's technique they have revealed the generational identification of groups: Soviet, transitional, Post-Soviet. By means of V. Iu. Kotliakov's technique it was established that family, communicative and altruistic senses were leading senses in the group of teenagers. The group of youth demonstrates cognitive, family senses, senses of self-realization, and also existential senses. In the group of pensioners there are existential, family and communicative senses. The authors 
draw a conclusion about statistically significant distinctions of senses in groups of different generational identities.

Keywords: generations, mentality, generational approach, sense sphere, change of generations.

Проблема преемственности поколений приобретает актуальность в связи с глобальными изменениями в стране. Попытки определения конструкта «поколение» были сделаны учеными в различных дисциплинах (A. Joshi, J. C. Dencker, 2010) [16]. Некоторые исследователи, такие как F. Giancola (2006), полагают, что «поколенческий подход может быть более популярен в культуре, чем в социальной науке» [15, с. 33]. Тем не менее, исследования поколений занимают выдающееся место в области социальных наук. Поколение определяется как «идентифицируемая группа, одного года рождения, пережившая значительные события в жизни, выпадающие на критические стадии ее развития» (B. R. Kupperschmidt, 2000) [17, с. 66]. Теоретически установлено, что различия между поколениями формируются под влиянием среды, социализации человека. Особое значение в поколенческом подходе имеют серьезные сдвиги в социальнокультурной среде с течением времени (S. M. Noble \& C. D. Schewe, 2003; J. M. Twenge \& S. M. Campbell, 2008) [18, 19]. Таким образом, поколения определяются теми историческими событиями, в которых формируется их ценностно-смысловая сфера, составляющая ядро поколенческой ментальности. Мы понимаем ментальность как совмещенность доминирующих, нормативно закрепленных систем значений, смыслов и ценностей образа мира поколения и социально-психологических характеристик, проявляющихся в его образе жизни.

В своем исследовании мы хотели показать, изменяются ли смысловые составляющие ментальности различных поколений.

Как отмечают И. В. Абакумова, Л. В. Косикова: «Смысложизненная концепция начинает складываться к подростковому возрасту, она может изменяться и трансформироваться на протяжении жизни человека, но на определенном этапе онтогенеза является достаточно устойчивой» [1, с. 8]. Это позволяет нам утверждать, что каждому поколению присуща специфическая иерархия смыслов. Рассмотрим представления о смыслах, сложившиеся в психологической науке.

А. Н. Леонтьев считал, что значения, к которым человек изначально равнодушен, встраиваются в его систему сознания только благодаря «пристрастности», когда они превратятся «в значение для субъекта», приобретут личностный смысл [8]. Личностный смысл связывает значения «с реальностью самой его жизни в этом мире. Смысл и создает пристрастность человеческого 
сознания» [там же]. Возникающие на поверхности переживания, по мнению ученого, «сигнализируют о личностном смысле событий» [там же], заставляют его остановиться и вдуматься в свою систему ценностей или пересмотреть ее. С данных позиций смысл выступает механизмом обращения к ценностям, связующим значения и ценности. При этом необходимо отметить, что смысл никогда не бывает завершенным как значение. «Смысл, таким образом, определяется более широким контекстом, чем значение» [10, с. 11]. «Смыслы обнаруживаются, а не придумываются» [14, с. 292].

Поскольку мы пишем о поколении как носителе ментальности, то важно понять, как взаимодействуют смыслы в поколенческой группе. М. М. Бахтин писал, что «встречающиеся в культуре смыслы не могут не соприкоснуться. Актуализироваться смысл может, только соприкоснувшись с другими смыслами» [2, с. 350]. П. Рикер отмечал, что герменевтика является «пониманием самого себя через понимание другого» [13, с. 25]. Это происходит в процессе общения, взаимодействия людей, при встрече их со-бытия.

Обратимся к рассуждениям М. Р. Гинзбурга, который выделяет «жизненное поле личности», представляющее собой «совокупность индивидуальных ценностей, смыслов и пространства реального действования - актуального и потенциального, охватывающего прошлое, настоящее и будущее [5].

«Базовые смысловые точки отсчета определяют для человека степень ценности тех или иных вещей, санкционируют мир его предпочтений, предопределяют характер его поступков в тех или иных ситуациях» [10, с. 91]. «Смыслы являются общими. Никто не может жить осмысленно в изоляции. Общность смысла характеризует все реальности без исключения. Любая смысловая структура является совместным способом понимания» [9, с. 13].

«Функция коммуникативных абстракций, коими являются значения, заключается в том, что посредством активации значений в голове партнера (достигаемой, в свою очередь, через активацию программы построения и посылку некоторых физических объектов-посредников, называемых знаками) можно ему намекнуть на какие-то иные, специфические, ситуативно значимые образы - смыслы. Тем самым реализуется возможность для членов одного коллектива "достраивать", расширять индивидуальные практические классификации, прибегая к использованию опыта других членов коллектива, то есть субъектно расширять субъективные смыслы» [12, с. 126]. Следовательно, И. Г. Петров придерживается позиции расширения субъектности за счет расширения репертуара смыслов посредством партнеров по коммуникации [12]. Предшествует этому состояние «полисемической и смысловой неопределенности», которая требует своего разрешения. 
Смену ценностных ориентаций предваряет смыслоумирание старых смыслов и рождение новых. Данный феномен рассмотрен А. К. Белоусовой [3]. Так, в совместной мыслительной деятельности один партнер посредством смыслопередачи «снижает значимость новых предметов и способствует образованию их новых психологических качеств» [3, с. 214]. В. Франкл писал, что «смысл объективен, по меньшей мере, постольку, поскольку его можно "найти", но нельзя дать» $[14$, с. 116]. То есть смыслы могут родиться и не могут быть переданы, но, возможно, смыслопередачу можно понимать как рождение своего смысла у партнера по взаимодействию под влиянием принятия смысла другого. «Человек постигает смыслы другого человека и формирует адекватные... смыслы», - утверждает А. К. Белоусова [3, с. 72]. В данной концепции основным источником трансформаций является смыслопередача.

Смыслы, которые придает человек объектам культуры, определяют его образ жизни, однако, по мнению В. Е. Клочко, и образ жизни придает смысл человеческой жизни. «Смыслы выступают как метаориентиры в характеристике субъекта» [5, с. 113].

По Д. А. Леонтьеву смыслы изменяются и порождаются в деятельности. Он, опираясь на понятие М. К. Мамардашвили «превращенной формы», определяет смысловые системы как превращенные формы жизненных отношений [9, с. 126].

Позиция субъекта определена в пространственно-временном континууме, что ограничивает его точку зрения, по мнению И. Г. Петрова [12, с. 128]. Исследователь выделяет в точке зрения целевую компоненту, знание, объективную область ее устремлений. Именно в точке зрения смыслы соединяются с ценностными ориентациями субъекта.

В рассматриваемом контексте важно понять, опираясь на взгляды В. Франкла, что при исчезновении традиций приходят в упадок ценности, но жизнь не теряет осмысленности, «уникальные смыслы остаются незатронутыми» [14, с. 295]. Но вместе с тем, если, согласно В. Е. Клочко, смыслы, как и значения, придают миру статус реального, то при потере смыслов, что сейчас фиксируется многими исследователями, мир также теряет реальность. При этом мы считаем, что теряются именно смыслы традиционной ментальности.

М. М. Бахтин определил «смысл» как то, что отвечает на какой-то вопрос [2]. Требование различать смысл-истину, смысл-цель и смысл-ценность выдвинул в числе первых Е. Н. Трубецкой [6]. В контексте нашего исследования смысл понимается как смысл-цель, - то, к чему стремятся и что в этом стремлении обретают поколения.

Сравнение жизненных смыслов различных поколений составило цель нашего исследования. 
Исследование жизненных смыслов как элементов ментальности проведено нами посредством методики В. Ю. Котлякова [7]. В методике содержатся восемь категорий жизненных смыслов, представленных различными высказываниями, с которыми опрашиваемый должен согласиться или не согласиться: альтруистические, экзистенциальные, гедонистические, самореализации, статусные, коммуникативные, семейные, когнитивные. Выбор испытуемым высказываний различных категорий смыслов демонстрирует его ориентиры в жизни. Методический прием анализа самооценки социальной идентичности (Н. Л. Иванова) [6] позволяет получить представления о выраженности различных видов поколенческой идентичности: советской, переходной и постсоветской. Выбор испытуемым высказываний различных категорий смыслов демонстрирует его ориентиры в жизни.

Выборку составили 3 группы: подростки, молодежь, пенсионеры, - всего 600 человек г. Ростова-на-Дону.

С помощью методического приема Н. Л. Ивановой установлено, что в группах поколений по-разному представлена поколенческая идентичность (см. табл. 1). Советская и переходная идентичности представлены в группах пенсионеров и молодежи. Постсоветская идентичность представлена в группах подростков и молодежи. Небольшой процент респондентов затруднялись определиться со своей идентичностью.

Таблица 1

\section{Выраженность поколенческой идентичности в группах}

\begin{tabular}{|c|c|c|c|}
\hline $\begin{array}{c}\text { Тип } \\
\text { идентичности }\end{array}$ & $\begin{array}{c}\text { Кол-во } \\
\text { человек }\end{array}$ & Выборка & $\begin{array}{c}\text { Выраженность } \\
\text { В \% }\end{array}$ \\
\hline \multirow{2}{*}{$\begin{array}{l}\text { Советское } \\
\text { поколение }\end{array}$} & \multirow{2}{*}{130} & Пенсионеры & 50 \\
\hline & & Молодежь & 20 \\
\hline \multirow{2}{*}{ Переходное } & \multirow{2}{*}{230} & Молодежь & 30 \\
\hline & & Пенсионеры & 50 \\
\hline \multirow{2}{*}{ Постсоветское } & \multirow{2}{*}{180} & Подростки & 90 \\
\hline & & Молодежь & 50 \\
\hline Невыраженная & 60 & $\begin{array}{c}\text { Пенсионеры, } \\
\text { молодежь, } \\
\text { подростки }\end{array}$ & 10 \\
\hline
\end{tabular}

Обнаружены значимые различия, рассогласования по смыслам альтруизма в группе подростков (постсоветская идентичность), гедонизма и самореализации - в группе молодежи (переходная идентичность), когнитивные и экзистенциальные, семейные - в группе пенсионеров (советская идентичность) $(a<0,05)$. 
Наиболее согласованы семейные смыслы и экзистенциальные. Они являются ведущими в группе подростков. Смыслы удовольствия, экзистенциальные смыслы, когнитивные и самореализации являются ведущими в группе молодежи. В группе пенсионеров ведущими смыслами являются семейные и экзистенциальные. Альтруистические смыслы имеют приоритеты в группе подростков, но в группе молодежи вытеснены. Группа подростков имеет определенную внутреннюю готовность помогать другим людям, делать добро и улучшать мир. Это означает, что подростки более жертвенны, чем молодежь. Гедонистические смыслы вытеснены в группе подростков и пенсионеров, а в приоритете у молодежи. Следовательно, молодежь нацелена на получение удовольствия, у них большое желание испытывать счастье, получать как можно больше ощущений и переживаний. Также смыслы самореализации вытеснены у подростков и пенсионеров, а у молодежи в приоритете. Молодежь, таким образом, нацелена на совершенствование, осуществление себя, чтобы реализовать все свои возможности. Коммуникативные смыслы вытеснены у молодежи, но занимают серединное положение у подростков и пенсионеров. При этом у молодежи ценность «наличие верных и хороших друзей» получила низкие ранги. То есть коммуникация молодежи не направлена на установление дружественных связей. Та же тенденция просматривается в группе подростков. Подростки и пенсионеры имеют потребность быть с близкими людьми, чувствовать, что кому-то нужны, радоваться общению с другими.

В группе пенсионеров приоритетное положение занимают семейные смыслы. Следовательно, пенсионеры в большей степени нацелены на то, чтобы жить ради семьи, передать все лучшее детям, помогать своим родным и близким. При значимости ценности счастливой семейной жизни в группе девушек наблюдается потеря смысла семьи. В группе юношей ценность и смысл семьи согласуются.

Как у подростков, так и у студенческой молодежи и пенсионеров когнитивные смыслы стоят на последних местах. То есть они не готовы к познанию себя, своей жизни и Бога. Настоящее время для указанных групп не связано с познанием, а в большей мере с созиданием. Это, видимо, характерная особенность современной ментальности поколений. Отсутствие когнитивных смыслов в актуальном поле указанных групп свидетельствует о том, что когнитивные жизненные смыслы не связаны с их самоопределением. Познавательное самоопределение связано со связями и способностями устанавливать отношения. Налицо рассогласование когнитивных смыслов и целей у представителей молодежи и подростков. Экзистенциальные смыслы наиболее актуальны для группы пенсионеров. Пенсионеры стремятся к свободе, к жизни и любви. Статусные смыслы вытесняются молодежью и принимаются, занимая средние значения, в группе девочек-подростков и пенсионеров. 
Из результатов следует высокая преемственность в смыслах подростков и пенсионеров начала XXI в. по семейным, альтруистическим и коммуникативным жизненным смыслам. Также существует преемственность в экзистенциональных смыслах молодежи и пенсионеров начала XXI в. и расхождение в других.

Полученные данные по смысловым составляющим ментальности подростков, пенсионеров и молодежи можно сравнить с результатами исследования 80-го г. XX в. Г. В. Папаян [11]. Автор сравнил людей разных поколений (всего 476 человек) по идеалам мировоззрения. Молодежь и пенсионеры 1980 г. основным идеалом, в какой-то мере смыслом, полагают труд, затем личное счастье и потом карьеру. Причем разрыв между карьерой и личным счастьем выше у пенсионеров 80-х гг. Жизненные смыслы семьи, альтруизма и коммуникации являются ведущими в группе подростков начала XXI в. В сравнении с подростками 80-х гг. отсутствуют когнитивные смыслы. Экзистенциальные смыслы, когнитивные, удовольствия и самореализации являются ведущими в группе молодежи. В группе молодежи 80-х гг. XX в. труд и счастье на первом месте, а затем следует карьера. В группе пенсионеров ведущими смыслами являются семейные и экзистенциальные. Следовательно, в группе пенсионеров, в сравнении с пенсионерами 80-х гг., выделены схожие смысловые основания.

Смысловое поле поколений показало основные расхождения в следующих смыслах: в группе подростков ведущими выступили семейные, коммуникативные и альтруистические смыслы. В группе молодежи представлены когнитивные, семейные, смыслы самореализации и экзистенциальные смыслы. В группе пенсионеров - экзистенциальные, семейные и коммуникативные. То есть, основные расхождения в названных группах были в когнитивных, коммуникативных, самореализации и альтруистических смыслах. Таким образом, наблюдается некоторая преемственность в смыслах поколений со схожей поколенческой идентичностью, но и расхождения, если поколенческая идентичность групп не совпадает.

\section{Литература}

1. Абакумова И. В., Косикова Л. В. Особенности смысловой сферы подростков в условиях включенного обучения // Российский психологический журнал. - 2009. - Т. 6. - № 5. - С. 7-14.

2. Бахтин М. М. Проблемы поэтики Достоевского. - М.: Художественная литература, 1972.

3. Белоусова А. К. Самоорганизация совместной мыслительной деятельности. - Ростов н/Д: Изд-во РГПУ, 2002.

4. Галажинский Э. В., Клочко В. Е. Самореализация личности: системный анализ. - Томск: Изд-во Томского университета, 1999. 
5. Гинзбург М. Р. Психологическое содержание личностного самоопределения // Вопросы психологии. - 1994. - № 3. - С. 43-52.

6. Иванова Н. Л., Румянцева Т. В. Социальная идентичность: теория и практика. - М.: СГУ, 2009.

7. отляков В. Ю. Методика исследования системы жизненных смыслов // Сибирская психология сегодня: Сборник научных трудов. - Кемерово: Кузбассвузиздат, 2003. - Вып. 2. - С. 18-21.

8. Леонтьев А. Н. Лекции по общей психологии. - М.: Смысл; КДУ, 2005.

9. Леонтьев Д. А. Психология смысла. Природа, структура и динамика смысловой реальности. - М.: Смысл, 1999.

10. Лобок А. М. Антропология мифа. - Екатеринбург: Отдел образования администрации октябрьского района, 1997.

11. Папаян Г. В. Опыт когортного анализа образа жизни // Социологические исследования. - 1981. - № 4. - С. 114-118.

12. Петров И. Г. Субъект и его характеристики в научной парадигме и аксиологии // Человек как субъект культуры / Отв. ред. Э. В. Сайко. - М.: Наука, 2002. - С. 112-130.

13. Рикер П. Конфликт интерпретаций: Очерки о герменевтике. - М.: Канон-пресс-Ц; Кучково поле, 2002.

14. Франкл В. Человек в поисках смысла. - М.: Прогресс, 1990.

15. Giancola F. The generation gap: more myth than reality // Human Resource Planning. - 2006. - 29 (4). - P. 32-37.

16. Joshi A., Dencker J. C., Franz G. \& Martocchio J. J. Unpacking generational identities in organizations // Academy of Management Review. - 2010. 35 (3). - P. 392-414.

17. Kupperschmidt B. R. Multigeneration employees: strategies for effective management // The Health Care Manager. - 2000. - 19 (1). - P. 65-76.

18. Noble S. M. \& Schewe C. D. Cohort segmentation: an exploration of its validity // Journal of Business Research. - 2003. - 56 (12). P. 979-987.

19. Twenge J. M. \& Campbell S. M. Generational differences in psychological traits and their impact on the workplace // Journal of Managerial Psychology. - 2008. - 23. - P. 862-877.

\section{References}

1. Abakumova I. V., Kosikova L. V. Osobennosti smyslovoi sfery podrostkov v usloviiakh vkliuchennogo obucheniia [Features of teenagers's sense sphere in conditions of inclusive education]. Rossiiskii psikhologicheskii zhurnal - Russian Psychological Journal, 2009, V. 6, no. 5, pp. 7-14. 
2. Bakhtin M. M. Problemy poetiki Dostoevskogo [Problems of Dostoyevsky's poetics]. Moscow, Khudozhestvennaia literature Publ., 1972.

3. Belousova A. K. Samoorganizatsiia sovmestnoi myslitel'noi deiatel'nosti [Self-organization of the joint cognitive activity]. Rostov-on-Don, Rostov State Pedagogical University Publ., 2002.

4. Galazhinskii E. V., Klochko V. E. Samorealizatsiia lichnosti: sistemnyi analiz [Self-realization of personality: system analysis]. Tomsk, Tomsk University Publ., 1999.

5. Ginzburg M. R. Psikhologicheskoe soderzhanie lichnostnogo samoopredeleniia [Psychological content of personal self-determination]. Voprosy Psychologii - Approaches to Psychology, 1994, no. 3, pp. 43-52.

6. Ivanova N. L., Rumiantseva T. V. Sotsial'naia identichnost': teoriia i praktika [Social identity: theory and practice]. Moscow, SGU Publ., 2009.

7. Kotliakov V. lu. Metodika issledovaniia sistemy zhiznennykh smyslov [The technique of research of the system of life's senses]. Sibirskaia psikhologiia segodnia: Sbornik nauchnykh trudov - Siberian Psychology Today: Collection of Scientific Works, 2003, no. 2, pp. 18-21.

8. Leont'ev A. N. Lektsii po obshchei psikhologii [Lectures on general psychology]. Moscow, Smysl Publ., 2005.

9. Leont'ev D. A. Psikhologiia smysla. Priroda, struktura i dinamika smyslovoi real'nosti [The psychology of sense: nature, structure and dynamics of sense reality]. Moscow, Smysl Publ., 1999.

10. Lobok A. M. Antropologiia mifa [Anthropology of a myth]. Yekaterinburg, Department of Education and Administration of Oktyabrsky District Publ., 1997.

11. Papaian G. V. Opyt kogortnogo analiza obraza zhizni [The experience of the cohort analysis of the way of life]. Sotsiologicheskie issledovaniia-Social Researches, 1981, no. 4, pp. 114-118.

12. Petrov I. G. Sub"ekt i ego kharakteristiki v nauchnoi paradigme i aksiologii. Chelovek kak sub"ekt kul'tury [The subject and his/her characteristics in a scientific paradigm and axiology. The person as a subject of culture]. Moscow, Nauka Publ., 2002, pp. 112-130.

13. Riker P. Konflikt interpretatsii: Ocherki o germenevtike [The conflict of interpretations: Sketches of hermeneutics]. Moscow, Kanon-press-Ts, Kuchkovo pole Publ., 2002.

14. Frankl V. Chelovek v poiskakh smysla [Man's search for meaning]. Moscow, Progress Publ., 1990.

15. Giancola F. The generation gap: more myth than reality // Human Resource Planning. - 2006. - 29 (4). - P. 32-37. 
16. Joshi A., Dencker J. C., Franz G. \& Martocchio J. J. Unpacking generational identities in organizations // Academy of Management Review. - 2010. 35 (3). - P. 392-414.

17. Kupperschmidt B. R. Multigeneration employees: strategies for effective management // The Health Care Manager. - 2000. - 19 (1). - P. 65-76.

18. Noble S. M. \& Schewe C. D. Cohort segmentation: an exploration of its validity // Journal of Business Research. - 2003. - 56 (12). - P. 979-987.

19. Twenge J. M. \& Campbell S. M. Generational differences in psychological traits and their impact on the workplace // Journal of Managerial Psychology. 2008. - 23. - P. 862-877. 